\title{
BMJ Open When to break the news and whose responsibility is it? A cross-sectional qualitative study of health professionals' views regarding disclosure of BRCA genetic cancer risk
}

\author{
Alison Luk Young (D) , ${ }^{1,2}$ Phyllis N Butow, ${ }^{1}$ Katherine M Tucker, ${ }^{3,4}$ \\ Claire E Wakefield, ${ }^{2,5}$ Emma Healey, ${ }^{6}$ Rachel Williams ${ }^{3,4}$
}

To cite: Young AL, Butow PN, Tucker KM, et al. When to break the news and whose responsibility is it? A crosssectional qualitative study of health professionals' views regarding disclosure of BRCA genetic cancer risk. BMJ Open 2020;10:e033127. doi:10.1136/ bmjopen-2019-033127

- Prepublication history for this paper is available online. To view these files, please visit the journal online (http://dx.doi org/10.1136/bmjopen-2019033127).

Received 22 July 2019

Revised 13 November 2019

Accepted 25 November 2019

Check for updates

(c) Author(s) (or their employer(s)) 2020. Re-use permitted under CC BY-NC. No commercial re-use. See rights and permissions. Published by BMJ.

For numbered affiliations see end of article.

Correspondence to

Alison Luk Young;

ayou1666@uni.sydney.edu.au

\section{ABSTRACT}

Objectives Disclosure of a hereditary condition in the family poses notable challenges for patients who often seek the assistance of genetic health professionals (GHPs). This study aimed to investigate GHPs' opinions about the ideal time for disclosure to offspring and their responsibility to at-risk relatives.

Design Cross-sectional qualitative study.

Setting Genetic familial cancer clinics related to mostly secondary and tertiary care hospitals and centres in urban, regional and rural areas across all states of Australia. Participants GHPs ( $\mathrm{N}=73$ ) including clinical geneticists, genetic counsellors, medical specialists, nurses, surgeons and mental health specialists (eg, psychiatrists, psychologists) who had worked with BRCA1 and BRCA2 families for an average of 9 years.

Results Focus groups and interviews were transcribed and analysed thematically. GHPs perceived that life stage, maturity, parents' knowledge and capacity to disseminate information influenced parent-offspring disclosure. In general, GHPs recommended early informal conversations with offspring about a family illness. GHPs considered that facilitation of disclosure to relatives using counselling strategies was their responsibility, yet there were limitations to their role (eg, legal and resource constraints). Variability exists in the extent to which genetic clinics overcome challenges to disclosure.

Conclusions GHPs' views on the ideal time for the disclosure of genetic risk are generally dependent on the patient's age and relative's ability to disclose information. A responsibility towards the patient and their at-risk relative was widely accepted as a role of a GHP but views vary depending on legislative and specialty differences. Greater uniformity is needed in genetic procedural guidelines and the role of each discipline (eg, geneticists, genetic counsellors, oncologists, nurses and mental health specialists) in genetic clinics to manage disclosure challenges.

\section{BACKGROUND}

Identifying a BRCA1 or BRCA2 (hereafter $B R C A 1 / 2)$ pathogenic variant in the family and informing relatives can be a challenge,

\section{Strengths and limitations of this study}

- This study provides one of the largest cohort of Australian genetic health professionals, with a detailed, in-depth approach to responsibility and confidentiality concerns.

- The findings extend on previous literature by focusing on two major genetic disclosure issues: ideal age of disclosure and the extent to which health professionals are responsible to warn at-risk relatives of their genetic cancer risk

- The study was limited to focus primarily on the disclosure of BRCA1 or BRCA2 genetic test results.

- A qualitative approach was taken to understand the challenges of disclosure.

- Highlights the variability in clinical practices across different legislative contexts and a need for clearer policies and role definitions.

since most people do not want to be a 'bearer of bad news'. Yet such information can have far-reaching implications for a relative's decision regarding risk management, lifestyle and family planning.

Genetic health professionals (GHPs) often work with families trying to navigate parentoffspring communication about genetic risk, commonly around when, how and what information to give, particularly the ideal age for disclosure. ${ }^{1}$ Factors, such as age, gender and the type of genetic condition, can influence offspring's understanding of genetic information. ${ }^{2} 3$ GHPs are also concerned about non-disclosure to offspring, which does occur, although less commonly than to extended relatives. ${ }^{4}$ Reasons for nondisclosure include: parental guilt, fear of burdening others and a relative's inability to cope. ${ }^{5}$ Approximately one-third of patients want GHP involvement during the family 
communication process, ${ }^{4} 6$ especially when families are emotionally and geographically distant. ${ }^{6}$ Offspring have also reported a preference for GHPs to disclose a hereditary condition in the family as opposed to parents. ${ }^{7}$ Yet the extent to which GHPs are responsible for ensuring appropriate disclosure is a matter of debate. According to Parker and Lucassen ${ }^{8}$ considering who owns genetic information is a matter of two viewpoints, namely, as belonging to the individual (personal account model) or belonging to the family (joint account model). From a personal account standpoint, genetic information is confidential unless there is strong reason for disclosure, whereas from a joint account viewpoint, genetic information is familial information, assuming justice to all members and is communicable unless there is strong reason for non-disclosure. In Australia, the latter is not a widespread viewpoint.

Despite the prevalence of studies exploring family communication of genetic information, ${ }^{9}$ very few studies explore GHPs' opinions on their responsibility to at-risk relatives. A recent systematic review ${ }^{10}$ found that across eight countries and varying heritable illnesses, GHPs generally felt some sense of responsibility to inform their patients' relatives about their genetic risk. Yet a range of moral, legal and practice-related arrangements reportedly made it challenging to act on their perceived responsibility. Of the nine studies in the review, none specifically explored GHPs' responsibility towards patients' relatives. A recent study, therefore, aimed to address this gap by conducting focus groups with UK GHPs. ${ }^{11}$ GHPs in the UK were concerned about the difficulty in distinguishing between genetic and personal information thereafter potentially breaching confidentiality through disclosure and more broadly, reported a need for national consensus on following the UK guidelines from the Joint Committee on Medical Genetics. According to these guidelines, GHPs explore family relationships, encourage family communication and assume that responsibility of disclosure lies with the patient.

Under the legislative guidelines of some countries, ${ }^{10}$ when patients do not provide consent for the disclosure of genetic information, GHPs can make contact with at-risk relatives.

Both Australian and UK guidelines encourage GHPs to take reasonable steps to obtain consent and consider the potential consequences of disclosure when consent is not provided. ${ }^{12} 13$ According to current Australian guidelines from the National Health and Medical Research Council, a GHP can disclose genetic information to an at-risk relative without the patient's consent in specific circumstances. This exemption applies for 'incurable' conditions which are 'preventable' or include 'treatable manifestations' (eg, depression), in which 'specific management' or 'treatment' can 'lessen or prevent' the threat of disease or distress (National Health and Medical Research Council, p42). ${ }^{12}$ Nevertheless, there is a lack of uniformity across Australia in how these guidelines are followed and upheld in clinical practice. ${ }^{14}$ South
Australian genetic services ${ }^{15}$ for example, provide family letters to at-risk relatives to inform them of an increased risk, with the patient's consent but without the recipient's consent, whereas the rest of Australia do not make provisions for direct contact with relatives. The extent to which Australian GHPs within public hospitals consider it their role to assist families with disclosure is currently unclear. The purpose of the current study was to understand the role of GHPs (in the context of this study, GHPs refers to clinical geneticists and genetic counsellors, and more broadly, health professionals who have worked closely with patients with a BRCA1 or BRCA2 genetic risk) in assisting families with disclosure of genetic cancer risk. Specifically, two research questions guided the study: (1) When is the best time to tell offspring about their genetic risk? and (2) Who is responsible to inform relatives of their genetic risk?

\section{METHODS}

Patient and public involvement statement

No patients involved.

\section{Study participants and recruitment}

Eligible GHPs (eg, clinical geneticist, genetic counsellors, nurses, oncologists and mental health specialists) who had worked with $B R C A 1 / 2$ families from familial cancer centres within all Australian states. A PhD candidate with several years' experience in qualitative research (ALY) presented the study to potential GHP participants during family cancer clinic meetings and/or emailed study details. Interested GHPs were then recontacted to arrange a suitable time for participation in a focus group or interview. Recruitment continued until theoretical saturation was achieved. ${ }^{16}$

\section{Procedures}

GHPs completed a questionnaire primarily collecting demographic data, and then took part in a focus group or interview. Focus groups (2-8 individuals) were held in-person or via video teleconferencing in 2017, during familial cancer clinic meetings or at a time convenient for participants. Semi-structured telephone or face-to-face interviews were completed with participants unable to attend a focus group. Three qualitative researchers (ALY, PNB and CEW) conducted focus groups and interviews that ranged in duration from 15 to $77 \mathrm{~min}$, depending on the time availability of participants.

\section{Data analysis}

Focus groups and interviews were transcribed verbatim and underwent data-driven analysis by three authors (ALY, PNB and RW) guided by thematic analysis ${ }^{17}$ using NVivo V.11 computer software to map themes. Consideration was given to whether individuals participating in one method (ie, focus groups) differed in relation to the experiences discussed in the other method (ie, interviews). Emphasis was placed on the themes mentioned by the majority of 
Table 1 Sample characteristics

\begin{tabular}{|c|c|}
\hline Health professionals $(n=73)$ & No (range) \\
\hline Mean age in years at interview (range) & $39.81(23-64)$ \\
\hline Average years practising (range) $)^{\star}$ & $8.55(0.50-23)$ \\
\hline $\begin{array}{l}\text { Average hours each week in direct } \\
\text { contact with patients at-high risk of } \\
\text { breast/ovarian cancer (range) }\end{array}$ & $7.53(0.05-27.50)$ \\
\hline Cultural background $\dagger$ & $\mathbf{N}(\%)$ \\
\hline Caucasian & $63(86.30)$ \\
\hline Other & $9(12.33)$ \\
\hline \multicolumn{2}{|l|}{ Marital status $†$} \\
\hline Single & $19(26.03)$ \\
\hline Married & $45(61.64)$ \\
\hline De facto/partnered/engaged & 7 (9.59) \\
\hline Other & $1(1.37)$ \\
\hline \multicolumn{2}{|l|}{ Employment $†$} \\
\hline Genetic counsellor & 59 (80.82) \\
\hline $\begin{array}{l}\text { Other (eg, geneticists, nurses, } \\
\text { oncologists, mental health } \\
\text { specialists) }\end{array}$ & $13(17.81)$ \\
\hline
\end{tabular}

*Missing demographic data $(n=3)$.

†Missing demographic data $(n=1)$.

participants and data that raised novel lines of inquiry, reflecting unique subthemes (eg, rurality, specialists). Three authors (ALY, PNB and RW) analysed the first six transcripts by rereading each transcript, generating codes and developing overall themes which were then organised into a thematic 'map'. Differences in coding were resolved by consensual discussion. Subsequent transcripts were analysed according to the 'map' resulting in a final set of themes. Focus group or individual interview identification (eg, FG4 or II4) are provided below.

\section{RESULTS}

\section{Sample characteristics}

Of 91 eligible GHPs invited, 73 consented and participated in the study. Demographic characteristics are provided in table 1 .

\section{When is the best time to tell offspring about their genetic risk?}

\section{Depending on the offspring}

GHPs had different arguments for and against disclosing genetic status to offspring earlier than the age of 18 , at the age of 18 and at the age of 25 onwards. Most GHPs reported that earlier was better to allow time for the offspring to adjust to, process and research information about their genetic risk before making decisions about medically mitigating their risk. Informing offspring as the conversation arises, in an age-appropriate manner, was commonly encouraged: 'in an ideal situation it should be a progressive discussion over time' (FG1). GHPs argued that if information about genetic risk is withheld, offspring might hear about it inadvertently from relatives and through GHPs during unrelated appointments, placing strain on the parent-offspring relationship. A few GHPs said that informing offspring in their mid-teenage years (15-17 years old) was ideal: 'probably mid-teens, and the reason why [is] to be aware [that] they can be breast aware, not breast alarmed and breast paranoid' (II15). Planning to inform offspring at the age of 18, or 'saving it up as an 18th birthday present' (FG9), was considered unhelpful and described as 'dropping the bombshell' (FG3).

In contrast, some GHPs felt that disclosure should be related to when it could inform testing/screening behaviour or decision making, and therefore, advocated disclosure at an older age ( $>20$ years). The recommended breast screening age for BRCA1/2 carriers is 30 within Australia. ${ }^{18}$ In relation to the patient's mental health, some GHPs said that disclosure at a young age can lead to prolonged worry, since the time between disclosure and screening is longer compared with their older counterparts. However, others disagreed with this stance stating that older patients can be more anxious if their parents informed them later due to the immediacy of action needed to mitigate risk. Some GHPs noted that parents may not be alive when their offspring reached the recommended age for screening or testing, and therefore disclosure, and possibly testing, should occur earlier. Subsequent, shifts in opinions were discussed, 'it used to be you don't do anything until you're going to use the information. And my original teaching was that you don't do genetic testing till a month before they're due to start screening...we now know that that isn't necessarily the best way of offering genetic testing' (FG1).

Other reasons some GHPs advocated disclosure at an older age were that young adults are considered generally more mature and receptive towards genetic information than younger offspring. Furthermore, the parent-offspring relationship is likely to change to an adult-adult pattern of relating as offspring age, which can be considered 'on a more even level' (FG4), allowing the young adult to be autonomous in their responses to genetic information and testing decisions. Disclosure at an older age was considered advantageous to avoid having offspring incorporate the pathogenic variant into their identity. A final justification for withholding information until adulthood was the potential for inappropriate medical management of young adults by GHPs in response to anxious younger adults insistent to have testing: 'they can be inappropriately managed if they're aware of this information from a young age...privately... [and] publicly...a breast surgeon will often screen younger women' (FG7).

Some GHPs recommended disclosure at key points related to genetic risk when offspring was in any case probably aware of health problems and emotional distress in the family, such as when a parent was diagnosed and being treated for cancer, or having surgery. 
Other GHPs said they did not recommend a time or age for disclosure, rather they spoke about taking a caseby-case approach, taking into account the unique characteristics of each individual, life experiences and family dynamics.

\section{Depending on the parent}

Some GHPs emphasised that disclosure should depend on the parent's decision about when and how they want to tell their offspring: 'parents know their child best of all and they would be in the best position to judge' (FG22). Parents can use their intuition to decide on the timing of disclosure and skilfully navigate around stressful events (eg, cancer diagnosis or anniversaries). Yet other GHPs felt that some parents' negative experience with genetic services could hinder timely and effective disclosure. For example, 'it's often a red flag when you have someone who's not [coped with the testing process]...if they've got a lot of emotional turmoil going on they kind of can 'project' that and expect that their children will react the same way and perhaps think that their kids can't cope' (FG4). GHPs also reported that parents may not understand the seriousness of sharing hereditary cancer information with families, may have forgotten about their results from a research study, and can potentially still be trying to process the information for themselves.

\section{Who is responsible to inform relatives about their genetic risk?}

GHPs are responsible to facilitate and support family communication

Many GHPs agreed that they were responsible for facilitating family communication by using a range of strategies to support probands (ie, during diagnostic testing) and relatives (ie, during predictive testing) to talk to their offspring and relatives (see table 2 for full list of strategies). Fact sheets were referred to most often as a resource to provide probands to assist with disclosure but was considered too generic or not user-friendly by some. GHPs also admitted to treating families differently depending on the type of test, 'I'm probably not as active in makingsure the information gets out there with the predictive (Predictive testing is the testing of a relative after a pathogenic variant has already been identified in the proband) as I am [with probands who are the first individual with a pathogenic variant to be identified in the family]' (FG7).

GHPs reported that assessment of family communication processes should start early in the consultation; for geneticists and genetic counsellors this involved pretest counselling, for nurses and mental health specialists this was during the first consultation and for oncologists this was at the time of talking about genetic testing to cancer patients. Assessment included exploring family dynamics (eg, estrangement, lack of communication), emotional responses that could impede communication (eg, guilt, fear) and assessing the proband's ability to disclose information to relatives (eg, clarify their understanding, coping skills). Building rapport with the patient is an important 'initial foundation' (FG20) to help patients with their communication with families.

GHPs advocated for gently preparing probands for the possibility that they could have a positive test result, and if so, to consider to whom, what and when they would disclose their results. When parents were finding it difficult to communicate to their offspring, GHPs offered to have the offspring join the parent's consultations, or provide subsequent over-the-phone consultations with the offspring and/or a separate consultation for the offspring to obtain more information. Family group consultations were also recommended to facilitate communication and address concerns with the relevant relatives present. Such consultations allow all members of the family to be informed simultaneously. Having another family member can lead to greater clarification of information: 'someone [can] obviously pick something up...[that] they then explained... [to each other] in a way that helps' (FG21). However, some GHPs were also concerned about the practicality of implementing family group consultations in the current public health model. In some cases when disclosure in families were not occurring, some GHPs were willing to 'take it upon themselves' to see that the adult children involved [were] informed of their risk, So you're protecting the rights of the child as well' (FG12).

\section{Different clinics, different responsibility}

The work culture, resources and expectations within particular genetic services influenced GHPs' views about disclosure to relatives: 'the scope of your role changes with whatever clinical service you are working with' (FG2). Some clinical teams placed greater emphasis on disclosure to at-risk relatives. For example, working within high-risk clinics provided some opportunities for nurses to explore disclosure, whereas some genetic counsellors reported, 'working in a busy clinical service in the public system really limits us in terms of our capacity of what we can do' (II14). Emphasis was placed on young at-risk relatives' personal responsibility, with one clinical geneticist saying, 'it's going to become too big for familial cancer centres to be able to hold onto these families and do the follow-up. I think it's going to have to shift out to personal responsibility' (FG10).

\section{Ultimately it is the families' responsibility}

Families were considered ultimately responsible for what they want to do with their own medical information. Confidentiality and autonomy were upheld by GHPs and if a patient chose to be private, this was respected. Some felt it was not their role to ensure disclosure beyond providing a family letter.

Conversely, others were of the mind that they would like to assist families with communication but were limited by time constraints and procedural barriers. Some GHPs believed GHPs should not feel guilty if disclosure did not occur in a family particularly since families do not always tell GHPs the truth and are unwilling to discuss family 
Table 2 Spontaneously reported techniques used by genetic health professionals to facilitate disclosure about a hereditary condition within the family

Techniques or resources

Equip parents with terminology to discuss genetic risk with offspring in an age-appropriate manner

Educate and correct used by GHPs misconceptions

\section{Examples}

Be mindful of an individual's cognitive capacity, emotional maturity and external factors before informing offspring. Use concepts that are easily understood by a particular age group.

- Children: Use basic concepts; brief explanations; be open about your medical appointments.

- Adolescence: casual conversations; allow for collaborative decision making.

- Young adults: provide details of genetic clinics; allow for autonomousdecision making.

Emphasise the significance of genetic results for the families' healthcare. Emphasis their right to know. Assess what information the patient has retained and capable of retelling others.

When patients discuss reasons for not wanting to inform relatives gently question and explore their reasons; such questioning might reveal myths that can be dispelled.

Provide reassurance and
encourage patients to
ask their at-risk relatives
to make contact with a
genetic service

At-risk relatives can make contact or attend an appointment at the genetic clinic for information-gathering purposes and not only for genetic testing.

Assess motivation or reasons for disclosure

Hypothetical scenarios and benefit/cost of nondisclosure

Frame positively

Perceive genetic testing as helpful and beneficial in leading to risk reduction of cancer through screening and surgery.

Normalise

Reassure that others commonly experience the same emotional responses and barriers. Provide examples of other families experiences and the strategies used to overcome similar barriers.

Alerting at-risk relatives by not disclosing the identity of a proband

At-risk relatives can be alerted about their cancer risk by informing them that they might be at risk of a condition without disclosing personal medical information.

Identify another relative to disclose information to family members

Used particularly when the proband/patient is unable to disclose to relatives.

Patients may want their relatives to test and Used when patients are reticent or actively non-disclosing to their at-risk relatives.

Illustrative quote

'Just briefly mention "In our family there is an increased cancer risk, [eg,] Aunty Stella has decided that she's going to look after herself this way [prophylactic surgery] But you've seen me I go to my screening every year and that's what I do". If [parents] go for annual screening... don't just hide that appointment or go when the children are at school so they don't know, just be open about the fact, "Oh I'm off for my annual screening today"' (FG9)

'Every family has certain health issues...this is just one thing that our particular family [has to do, for example, check-ups, etc]' (FG9)

'[Patient's come thinking there is] a pre-determined or that a concrete plan has been set in place of what [testing's] going to mean for them' (FG23)

'[Some] people...[with] no breast cancer in the family... still can't talk about it because, "We might all get breast cancer", even though no one has had breast cancer before... I don't think they can talk about [a] gene mutation or the cancer because I think for many people there are very intimately associated' (FG25)

'I say, "You don't need to worry about giving them al the ins and outs of what it means and what it means for them, they can speak to the local genetics service"...so I reassure them that they're not expected to be the expert for the family just to be the source of information about it' (FG9)

'I think about what motivates someone to want to tell their family early and what motivates them to withhold information - [it] is really important' (FG3)

'...try [to] think about the consequences of not disclosing to [your] daughter' (FG24)

'I often say to people, "You don't have any choice about what genes you pass on, but you do have a choice to share this information...this is something you can do... [that] you are in control of "'(FG4)

'Everybody brings in a different attitude to this, from sort of incredibly pragmatic to incredibly emotional, and that must provide the way you deal with that information in your family. There's no right or wrong it's just how you're wired to move forward' (FG4)

'[For example,] a woman does not want her family to know her [identity but wants them to know they are at risk, so making a] letter with de-identified information, which we can have them check [and write collaboratively with the patient] routinely' (FG19)

'If they can delegate the task...get your brother who is in touch with all these people or cousin...give the job of disseminating information to somebody else and then that way the patient can concentrate on their own health (FG1)

'Determined whether we know which side of the family the mutation is coming from' (FG12)
Discuss 'when', 'who', 'how' they will disclose
Identify ideal timing (eg, casually, avoid anniversaries/major events), who is at risk and what modality to use to communicate to relatives (eg, face to face, letter, online). 
Table 2 Continued

\begin{tabular}{|c|c|c|}
\hline $\begin{array}{l}\text { Techniques or resources } \\
\text { used by GHPs }\end{array}$ & Examples & Illustrative quote \\
\hline Role play & $\begin{array}{l}\text { Re-enact the discussion parents would have } \\
\text { with their relative, provide the vocabulary, } \\
\text { develop a plan and draw on how parents' have } \\
\text { disclosed difficult information in the past. }\end{array}$ & $\begin{array}{l}\text { 'I often say, "You best have.... phrase or something } \\
\text { you're going to say that you feel is age-appropriate for } \\
\text { your child"...you want to have a scenario whereby you } \\
\text { can communicate something that feels safe for the child } \\
\text { that is age-appropriate in terms of the language and you } \\
\text { probably don't want to minimise it or just brush it under } \\
\text { the carpet. You want to try and be honest' (FG4) }\end{array}$ \\
\hline Family letters & $\begin{array}{l}\text { Helpful when proband/patient is unable to } \\
\text { disclose to relatives or fearful of forgetting } \\
\text { important information. }\end{array}$ & $\begin{array}{l}\text { 'The letter help[s] them to share it with their family and } \\
\text { that kind of externalises it from them' (FG21) }\end{array}$ \\
\hline $\begin{array}{l}\text { Follow-up phone calls/ } \\
\text { letters/appointments }\end{array}$ & $\begin{array}{l}\text { Provided: (1) to clarify information provided } \\
\text { by proband/patient, ( } 2 \text { ) when the relative is } \\
\text { reaching an age when medical management } \\
\text { is recommended (eg, screening at } 30),(3) \\
\text { when proband/patient needs time to process } \\
\text { information (cognitively, emotionally). }\end{array}$ & $\begin{array}{l}\text { 'I say, "Make a plan... we'll discuss it over dinner or when } \\
\text { you are on a family outing and then I check in a few } \\
\text { weeks later, did you do that? how did it go? is there any } \\
\text { way you can think of doing it another way if you didn't get } \\
\text { opportunity to discuss it?"' (FG2) }\end{array}$ \\
\hline Social media & $\begin{array}{l}\text { Helpful if relatives are estranged, live overseas } \\
\text { or have minimal contact. }\end{array}$ & $\begin{array}{l}\text { 'They will say, "Oh, actually my relatives are overseas". } \\
\text { It's almost as though they're not part of the family } \\
\text { anymore, "They're so distant from me"' (FG4) }\end{array}$ \\
\hline
\end{tabular}

GHPs, genetic health professionals.

dynamics. Some familial issues are beyond a medical GHP's capacity (or consultation time) to discuss and requires psychological assistance. For example, a genetic counsellor said, 'Sometimes I think whatever's going on in their families is beyond what we as genetic counsellors can actually help with, which is unfortunate, but... considering the workload...you can only pour so much of your energy into one family' (FG20). Another common limitation GHPs discussed was having no control over what happens after a consultation, 'you've got no control over what's passed on and what isn't or how it's passed or whether facts and figures [are] mixed up' (FG10). Moreover, GHPs were also aware that advocating for disclosure was not beneficial in all cases, 'it's important to be aware of the fact that there could be positives and negatives [in] telling, but also positives and negatives in not telling' (II18). Situations in which information is withheld or difficult to navigate include cases when an at-risk relative has a mental health concern and/or cognitive disability.

\section{DISCUSSION}

The age at which disclosure should ideally begin is not a concern of BRCA1/2 families alone but is common among families with a hereditary condition. ${ }^{2}$ GHPs in this study recommended optimal time frames for disclosure of genetic risk to offspring, with the majority favouring early disclosure tailored to individual circumstances. Hereditary cancer can be introduced into the family story with a simple explanation about genetics, cancer and the benefits of testing. ${ }^{19}$ An example of such an explanation is that used for families with cystic fibrosis, terminology that normalises their condition such as, 'everyone possesses disease causing genes' (Cavanagh et al, p206). ${ }^{20}$ This method of dissemination is modelling to offspring that coping and adjustment to such information is possible. Having more time to process, discuss and ask questions during casual conversations is less anxiety provoking than being informed unexpectedly at an age when immediate medical action is required. ${ }^{21}$

According to Klitzman et $a l^{7}$ the reasoning behind GHPs' perspective about the ideal age for genetic testing and subsequent disclosure can fall under two categories: (1) the life stage or maturity of offspring and (2) the medical time course and benefit of the information at a given time. Age appropriateness was a key feature of early disclosure. According to Piaget's theory of cognitive development, children at approximately 11 years old reach the stage of 'formal operational thought', at which hypothesis testing and abstract reasoning develop. ${ }^{22}$ In theory, children at this stage can make inferences that if their parent is ill, then they too could become ill with the same illness. ${ }^{24}$ Thus, parents are recommended to consider their offspring's cognitive and emotional capacity before informing them about their risk, ${ }^{19}$ which may have different developmental trajectories depending on the temperament of the offspring. ${ }^{25}$ Parental consideration 
of disclosure of genetic status with young adults involves consideration of poignant life stage changes or communicating at certain junctures (eg, impending marriage or pregnancy). ${ }^{9}$ Parental capacity to inform offspring ${ }^{20}$ and their own experience or level of satisfaction with genetic testing may hinder communication, ${ }^{26}$ warranting the facilitation of communication by GHPs. ${ }^{27}$

GHP's facilitation of disclosure is generally agreed to be incorporated in their clinical practices (ie, table 2), expounding on previously reported strategies. ${ }^{11}$ Contrastingly, the opinions of some GHPs suggest that facilitation of disclosure is a peripheral requirement of their practice, other than providing a family letter passed from patient to relative. Patient autonomy, confidentiality and/or the law can also contribute to the reluctance to facilitate disclosure. ${ }^{10}$ Follow-up calls/appointments to address disclosure are considered worthwhile to revisit the topic of disclosure with families, particularly when legislative changes occur, ${ }^{28}$ yet resource and time constraints can make this impracticable. ${ }^{29}$

In South Australia, the genetic services send letters directly to at-risk relatives, with the patient's consent. Other research has shown benefits from direct contact with at-risk relatives. ${ }^{30}$ Studies involving a range of illnesses (eg, BRCA1/2, Lynch, Cowden syndrome) have shown that when GHP-mediated contact, uptake of testing was greater among at-risk relatives compared with when contact was patient-mediated. ${ }^{1531}$ A Western Australian study adopted a cascade screening process derived from an Australasian model of care for familial hypercholesterolaemia in accordance to local and national guidelines. Nurse-led initiation of contact with at-risk relatives, despite non-consent from probands, allowed for the identification of carriers in first-degree, second-degree and third-degree relatives. ${ }^{32}$ Recently GHPs working in French genetic clinics are legally permitted to offer a written document informing at-risk relatives of their risk, yet guidance about to whom this requirement extends to and how GHPs responsibility will be defined remains elusive. ${ }^{33}$ Yet GHPs are still apprehensive about changing their practices ${ }^{34}$ highlighting that a shift towards a 'jointaccount model' is not only a matter of legislative changes but also a matter of shifting viewpoints.

In this study, we found that GHPs' opinions regarding their responsibility towards at-risk relatives differed depending on four factors. First, a GHP's role and opinion were informed by the attitudes and expertise of the genetic clinic in which they worked, which varied between local health districts and states. Second, GHPs in each specialty were governed by their own legislation and ethical guidelines, including the overall framework and ethos in which they practiced, which emphasised family communication to a lesser or greater extent depending on the profession (eg, genetic counsellor vs medical oncologist). Third, GHPs generally reported a greater need to facilitate communication for probands who are the first in the family to be identified as a carrier since the burden of sharing information appears greater than those who have cascade testing, and therefore, can also be dependent on whether the patient has cancer or not. Fourth, statewide differences in health provision and legislation meant that clinics in South Australia can send genetic letters to relatives effectively, ${ }^{15}$ but GHPs in New South Wales are still cautious of potential litigation issues despite amendment of privacy principles in attempt to uniform Australian genetic practices. ${ }^{14}$

GHPs working in genetic clinics, many of whom are genetic counsellors, are governed by their respective professional guidelines and respective health district legislation. 'Non-directiveness' is a term used to describe GHP practices that are patient-centred and uphold the autonomous decisions of the patient. ${ }^{35}$ Yet within the context of cancer genetics in which evidence-based surgical treatments exist that effectively mitigate risk, adherence to such principles is questionable. ${ }^{36}$ The Task Force of the National Society of Genetic Counsellors has consequently excluded the term 'non-directiveness' in their definition of genetic counselling, emphasising instead on educating patients about testing implications for themselves and relatives. ${ }^{37} \mathrm{~A}$ shared decision-making approach is currently favoured. ${ }^{38}$

With the rise of genomic medicine and the subsequent need to educate the general public of the potential benefits and limitations of such knowledge, the question of who is responsible to inform the public is a wider healthcare concern. Contrary to the opinions of a small minority of GHPs in the current study who predict a shift to personal responsibility when managing at-risk relatives, the European Breast Cancer Council ${ }^{39}$ argues that the healthcare system will need to rise to the challenge and support future families in obtaining high-quality and timely information. It is already evident that without the input of cancer genetic clinics, at-risk relatives are not considering the potential limitations of a proposed test before choosing direct-to-consumer genetic testing. ${ }^{40}$ The lack of guidance and advice from medical professionals about their genetic risk ${ }^{40}$ further reinforces the need for genetic cancer clinics to clarify their responsibility for at-risk relatives.

\section{Practice implications}

A multidisciplinary approach to genomic medicine has been proposed to be effective in tackling the challenge of disclosure. ${ }^{28}{ }^{41}$ GHPs are currently supporting young at-risk relatives within high-risk clinics in Australia, but can also potentially allow for ongoing support of families struggling with disclosure difficulties. It is possible that during the consent conversation with a proband, GHPs can describe the joint account viewpoint towards familial information using the analogy of family members owning a joint bank account and having equal rights to the funds (information). ${ }^{8}$

Funding regulators are to emphasise fiscal and institutional backing of genetic clinics in order to sustain a multidisciplinary team approach and to manage the future role of GHPs in the preventive health of their 
patient's relatives. GHPs need to be having discussions, amongst themselves, but ideally nationally with policymakers, legal services and government, to advocate for more clarity about who owns genetic information-the patient or the family (personal vs joint account model) and greater clarity is needed on the definition of 'at-risk relatives', and the extent to which GHPs are responsible to inform them. The current approaches recommended to address disclosure of cancer risk in Australia are ad hoc; more guidance and standardisation of practices is needed by modifying guidelines that are better suited to local regulatory needs.

\section{Limitations}

This study focused primarily on GHPs' view of BRCA1/2 families' disclosure of genetic risk. Nevertheless, the topics covered were broad enough to have applicability and transferability to other adult-onset genetic health conditions (eg, familial hypercholesterolaemia) in which parents are also faced with the dilemma of disclosure, and in some cases they have similar consequences and riskmanagement options available (eg, Lynch syndrome). Genetic counsellors $(80 \%)$ provided the most input into discussions, and therefore, their practices were emphasised the most in the results. Further research is required, with larger samples of geneticists, surgeons, nurses and mental health specialists to further elucidate their opinion about their role in disclosure.

\section{CONCLUSION}

This Australian study reports on the ideal age of parentoffspring disclosure of genetic risk and GHPs' responsibility towards at-risk relatives. Our findings highlight the need for clearer policies regarding GHP's responsibility to relatives and to the community in terms of preventive health, including the need for more staff and fiscal support to sustain disclosure initiatives (eg, direct-contact letters).

\section{Author affiliations}

${ }^{1}$ The University of Sydney, Faculty of Science, School of Psychology, Centre for Medical Psychology \& Evidence-based Decision-making (CeMPED), Sydney, New South Wales, Australia

${ }^{2}$ Kids Cancer Centre, Sydney Children's Hospital Randwick, Sydney, New South Wales, Australia

${ }^{3}$ Prince of Wales Clinical School, Faculty of Medicine, University of New South Wales, Sydney, New South Wales, Australia

${ }^{4}$ Prince of Wales Hereditary Cancer Centre, Prince of Wales Hospital and Community Health Services, Sydney, New South Wales, Australia

${ }^{5}$ School of Women's and Children's Health, University of New South Wales, Sydney, New South Wales, Australia

${ }^{6}$ Illawarra Cancer Care Centre, Wollongong Hospital, Wollongong, New South Wales, Australia

\section{Twitter Alison Luk Young @AlisonYoungAU}

Funding This research received no specific grant from any funding agency in the public, commercial or not-for-profit sectors. ALY is supported by the School of Psychology Margaret Stewart Fund Scholarship. CEW is supported by a Career Development Fellowship from the National Health and Medical Research Council of Australia (APP1143767). The Behavioural Sciences Unit at the Kids Cancer Centre is proudly supported by the Kids with Cancer Foundation.

Competing interests None declared.
Patient consent for publication Not required.

Ethics approval The project was approved by the University of Sydney Human Research Ethics Committee (HREC 2017/011) which covered the participating hospitals.

Provenance and peer review Not commissioned; externally peer reviewed.

Data availability statement Data are available on reasonable request to the authors.

Open access This is an open access article distributed in accordance with the Creative Commons Attribution Non Commercial (CC BY-NC 4.0) license, which permits others to distribute, remix, adapt, build upon this work non-commercially, and license their derivative works on different terms, provided the original work is properly cited, appropriate credit is given, any changes made indicated, and the use is non-commercial. See: http://creativecommons.org/licenses/by-nc/4.0/.

ORCID iD

Alison Luk Young http://orcid.org/0000-0002-0810-4256

\section{REFERENCES}

1 Metcalfe A, Coad J, Plumridge GM, et al. Family communication between children and their parents about inherited genetic conditions: a meta-synthesis of the research. Eur J Hum Genet 2008;16:1193-200.

2 Rowland E, Metcalfe A. Communicating inherited genetic risk between parent and child: a meta-thematic synthesis. Int J Nurs Stud 2013;50:870-80.

3 Vears DF, Delany C, Massie J, et al. Why do parents want to know their child's carrier status? A qualitative study. J Genet Couns 2016;25:1257-66.

4 Aktan-Collan KI, Kääriäinen HA, Kolttola EM, et al. Sharing genetic risk with next generation: mutation-positive parents' communication with their offspring in Lynch Syndrome. Fam Cancer 2011;10:43-50.

5 Healey E, Taylor N, Greening S, et al. Quantifying family dissemination and identifying barriers to communication of risk information in Australian BRCA families. Genet Med 2017:19:1323-31.

6 Pentz RD, Peterson SK, Watts B, et al. Hereditary nonpolyposis colorectal cancer family members' perceptions about the duty to inform and health professionals' role in disseminating genetic information. Genet Test 2005;9:261-8.

7 Klitzman R, Thorne D, Williamson J, et al. Disclosures of Huntington disease risk within families: patterns of decision-making and implications. Am J Med Genet A 2007;143A:1835-49.

8 Parker M, Lucassen AM. Genetic information: a joint account? BMJ 2004;329:165-7.

9 Gaff CL, Clarke AJ, Atkinson P, et al. Process and outcome in communication of genetic information within families: a systematic review. Eur J Hum Genet 2007;15:999-1011.

10 Dheensa S, Fenwick A, Shkedi-Rafid S, et al. Health-care professionals' responsibility to patients' relatives in genetic medicine: a systematic review and synthesis of empirical research. Genet Med 2016;18:290-301.

11 Dheensa S, Fenwick A, Lucassen A. Approaching confidentiality at a familial level in genomic medicine: a focus group study with healthcare professionals. BMJ Open 2017;7:e012443.

12 National Health and Medical Research Council. Use and disclosure of genetic information to a patient's genetic relatives under section 95AA of the Privacy Act 1988 (Cth). Guidelines for health practitioners in the private sector. Canberra: National Health and Medical Research Council, 2014. https://www.nhmrc.gov.au/file/ 13181/download?token=j6xg0_li

13 Royal College of Physicians, Royal College of Pathologists, British Society for Genetic Medicine. Consent and confidentiality in genomic medicine: guidance on the use of genetic and genomic information in the clinic. Report of the joint Committee on genomics in medicine. 3rd edn. London: RCP, RCPath and BSGM, 2019.

14 Otlowski MFA. Disclosing genetic information to at-risk relatives: new Australian privacy principles, but uniformity still elusive. Med J Aust 2015;202:335-7.

15 Suthers GK, Armstrong J, McCormack J, et al. Letting the family know: balancing ethics and effectiveness when notifying relatives about genetic testing for a familial disorder. J Med Genet 2006;43:665-70.

16 Namey E, Guest G, McKenna K, et al. Evaluating bang for the buck: a cost-effectiveness comparison between individual interviews and focus groups based on thematic saturation levels. Am J Eval 2016;37:425-40. 
17 Braun V, Clarke V. Using thematic analysis in psychology. Qual Res Psychol 2006;3:77-101.

18 Cancer Institute NSW. Risk management for a female BRCA1 mutation carrier, 2018. Available: https://www.eviq.org.au/p/170 [Accessed 31 Jan 2020].

19 Werner-Lin A, Merrill SL, Brandt AC. Talking with children about adult-onset hereditary cancer risk: a developmental approach for parents. J Genet Couns 2018;27:533-48.

20 Cavanagh L, Compton CJ, Tluczek A, et al. Long-Term evaluation of genetic counseling following false-positive newborn screen for cystic fibrosis. J Genet Couns 2010;19:199-210.

21 Dennis A, Howell S, Cordeiro L, et al. "How should I tell my child?" Disclosing the diagnosis of sex chromosome aneuploidies. J Genet Couns 2015;24:88-103.

22 Piaget J. Part I: cognitive development in children: Piaget development and learning. J Res Sci Teach 1964;2:176-86.

23 Bibace R, Walsh ME. Development of children's concepts of illness. Pediatrics 1980;66:912-7.

24 Metcalfe A, Plumridge G, Coad J, et al. Parents' and children's communication about genetic risk: a qualitative study, learning from families' experiences. Eur J Hum Genet 2011;19:640-6.

25 Perlman SB, Pelphrey KA. Regulatory brain development: balancing emotion and cognition. Soc Neurosci 2010;5:533-42.

26 Lieberman S, Lahad A, Tomer A, et al. Familial communication and cascade testing among relatives of BRCA population screening participants. Genet Med 2018;20:1446-54.

27 Peshkin BN, DeMarco TA, Tercyak KP. On the development of a decision support intervention for mothers undergoing BRCA1/2 cancer genetic testing regarding communicating test results to their children. Fam Cancer 2010;9:89-97.

28 Derbez B, de Pauw A, Stoppa-Lyonnet D, et al. Supporting disclosure of genetic information to family members: professiona practice and timelines in cancer genetics. Fam Cancer 2017:16:447-57.

29 Forrest LE, Delatycki MB, Curnow L, et al. Genetic health professionals and the communication of genetic information in families: practice during and after a genetic consultation. Am J Med Genet A 2010;152A:1458-66.
30 Schwiter R, Rahm AK, Williams JL, et al. How can we reach at-risk relatives? efforts to enhance communication and cascade testing uptake: a mini-review. Curr Genet Med Rep 2018;6:21-7.

31 Sermijn E, Delesie L, Deschepper E, et al. The impact of an interventional counselling procedure in families with a BRCA1/2 gene mutation: efficacy and safety. Fam Cancer 2016;15:155-62.

32 Bell DA, Pang J, Burrows S, et al. Effectiveness of genetic cascade screening for familial hypercholesterolaemia using a centrally coordinated clinical service: an Australian experience. Atherosclerosis 2015;239:93-100.

33 d'Audiffret Van Haecke D, de Montgolfier S. Genetic diseases and information to relatives: practical and ethical issues for professionals after introduction of a legal framework in France. Eur J Hum Genet 2018;26:786-95.

34 Derbez B, de Pauw A, Stoppa-Lyonnet D, et al. Familial disclosure by genetic healthcare professionals: a useful but sparingly used legal provision in France. J Med Ethics 2019;45:811-6.

35 Elwyn G, Gray J, Clarke A. Shared decision making and nondirectiveness in genetic counselling. J Med Genet 2000;37:135-8.

36 Koch L, Nordahl Svendsen M. Providing solutions-defining problems: the imperative of disease prevention in genetic counselling. Soc Sci Med 2005;60:823-32.

37 Resta RG. Defining and redefining the scope and goals of genetic counseling. Am J Med Genet C Semin Med Genet 2006;142C:269-75.

38 Forbes Shepherd R, Browne TK, Warwick L. A relational approach to genetic counseling for hereditary breast and ovarian cancer. $J$ Genet Couns 2017;26:283-99.

39 Rutgers E, Balmana J, Beishon M, et al. European Breast Cancer Council manifesto 2018: Genetic risk prediction testing in breast cancer. Eur J Cancer 2019;106:45-53.

40 Roberts JS, Gornick MC, Carere DA, et al. Direct-To-Consumer genetic testing: user motivations, decision making, and perceived utility of results. Public Health Genomics 2017;20:36-45

41 Metcalfe A. Sharing genetic risk information: implications for family nurses across the life span. J Fam Nurs 2018;24:86-105. 